\title{
Pain in child patients: A review on managements
}

\author{
Seyedeh Mahsa Mahmoudinezhad Dezfouli, Shaqayeq Khosravi
}

(1) Department of Emergency Medicine, School of Medicine, Iran University of Medical Sciences, Aliasghar children Hospital, Tehran, Iran

This article is distributed under the terms of the Creative Commons Attribution Noncommercial License (CC BY-NC 4.0) which permits any noncommercial use, distribution, and reproduction in any medium, provided the original author(s) and source are credited.

\begin{abstract}
Pain has been known as one of the major universal health concerns about ill children, because of its morbidity and potential mortality. Pain suitable evaluation is a challenge in children because the verbalization is difficult. Low clinical information, few pediatric researches, and the worry of opioid side effects make difficult to provide satisfactory treatments. Many pharmacologic and non-pharmacologic strategies to manage pain exist for pediatric pain treatment. The purpose of this review article is to describe exhaustively pain mechanism, evaluation and management by review literature from January 2000 to January 2019 using PubMed, EMBASE, MEDLINE, LILACS databases. Pharmacological and integrative non-pharmacological therapies has been indicated in acute and chronic pain treatment. Opioids and opioid-sparing agents target nociceptive and neuropathic pain. With due attention to available results, an early combination of pharmacological and integrative non pharmacological treatments are indicated in children pain management.
\end{abstract}

Key Words: Pediatric pain, pain management, pain evaluation, opioid reduction therapy, nonpharmacological therapy

Eur J Transl Myol 30 (2): 291-296, 2020

According to the Institute of Medicine statement on Relieving Pain in America, acute and chronic pain is a major weekend problem in adulthood, ${ }^{1}$ but it is a major health concern in ill children, because of its morbidity and potential mortality. ${ }^{2}$ The acute pain is a body response to mechanical and thermal stimuli and to harmful chemical. Usually it is resolved after days or weeks. ${ }^{3}$ Chronic pain is an unmanageable pain that stands for three or more months, notwithstanding treatment. ${ }^{4}$

Suitable evaluation of pain is a challenge in children because their verbalization is difficult. ${ }^{5}$ Due to low clinical information, too few pediatric researches and worry of opioid side effects make arduous a satisfactory treatment. $^{3,6}$ A large proportion of admitted children have pain, particularly related to surgery. ${ }^{7}$ Indeed, pain recognition and assessment in children is difficult causing undesirable patient results. ${ }^{8}$ Improving analgesia in all patients is mandatory, by training the medical staff according to the World Health Organization (WHO) pain ladder application. Many pharmacologic and nonpharmacologic strategies exists for pediatric pain treatment, ${ }^{9}$ in particular for chronic children pain in abdominal and musculoskeletal diseases, cancer, vaseocclusive crises, and headaches. ${ }^{2,10,11}$ The basic treatment for acute postoperative pain in children can be performed with opioids. Opioids are also prescribed in patients with weakening chronic pain conditions. ${ }^{12}$ Notwithstanding opioids advantage for management of pain, some side effects such as cognitive dysfunction, constipation, psychiatric comorbidities, and respiratory depression can occur in this therapeutic procedure. ${ }^{13-15}$ Due to these side effect of opioids, multidisciplinary analgesia treatments increased. ${ }^{3}$ Concurrent use of pharmacological and integrative non-pharmacological treatment may decrease the need of opioid therapy. ${ }^{16}$

In this review, we summarize definitions of pain, its mechanisms, evaluation, and managements. A broad search was performed on biomedical and pharmacological bibliographic database such as PubMed, EMBASE, MEDLINE, and LILACS database, global independent network of Cochrane, Science Direct and global health library of Global Index Medicus (GIM). By referencing these databases, a comprehensive literature review was carried out combining the terms: pediatric pain, evaluation, mechanism, management and treatment for articles published from 2000 to 2019. A total of 284 articles were obtained. About 68 of them were deleted due to content not related to the objective of the study. After deleting other weak articles, 30 articles were selected for detailed review based on the fact that 


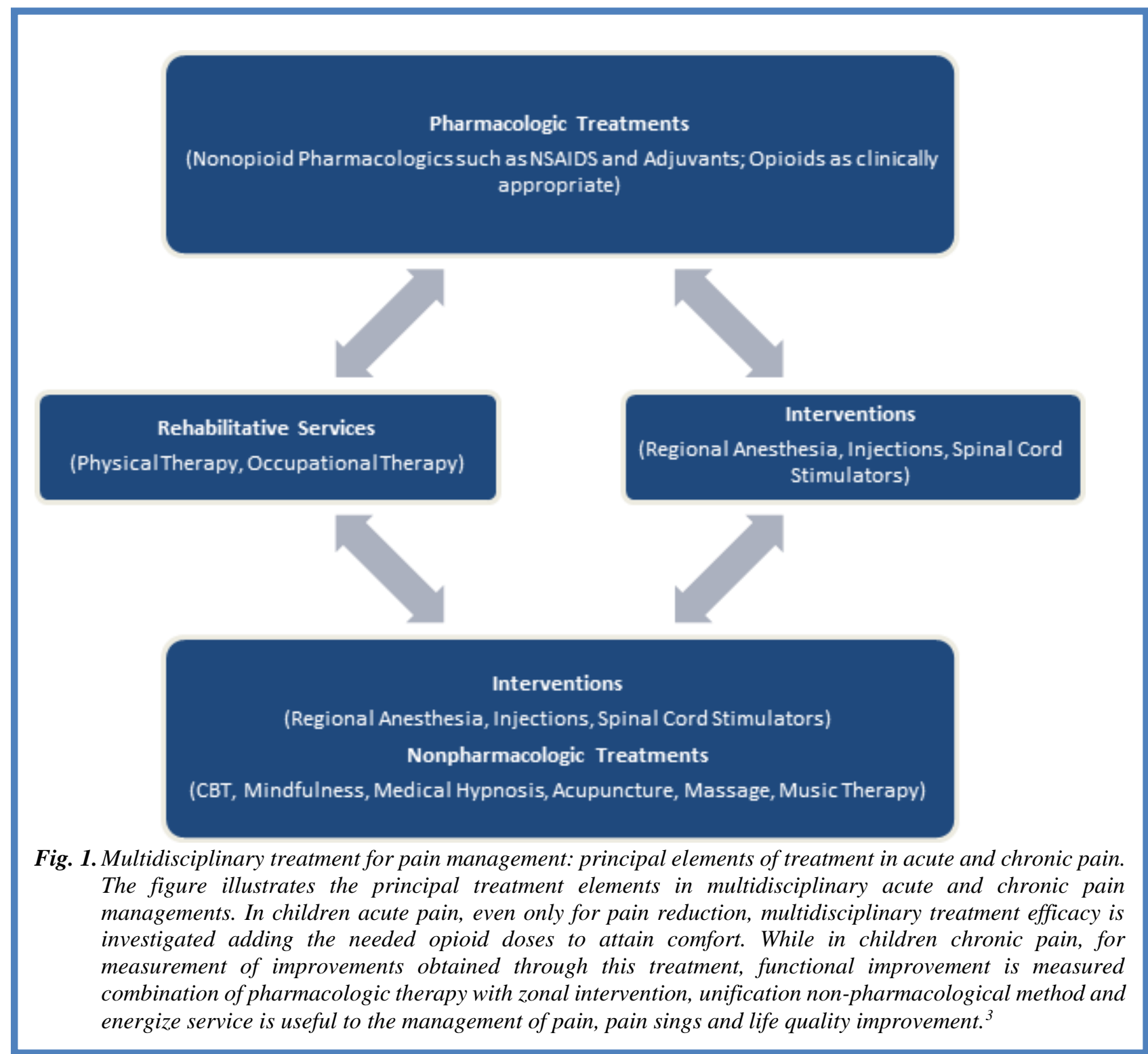

they appeared to be good examples of evidence-based medicine (EBM). A multitude of pain definitions exists, producing a very controversial issue. ${ }^{17}$ The most accepted is the one of the international association for the Study of Pain (IASP), that is "an unpleasant sensory and emotional experience associated with actual or potential tissue damage, or described in terms of such damage". ${ }^{18}$ In humanity and lawful area, pain is recognized as a serious scourge of humanity, therefore, its management is a fundamental human right dictatted by article 25 of the Human Rights. Pain may be also defined as: physical or mental and acute or chronic. Another classification of pain include the terms: musculoskeletal, inflammatory or mechanical/ compressive pain. ${ }^{8-21}$

Pain is sensory or discriminative, affective or emotional, cognitive and behavioral. The pain follows the sensory system, whose afferent pathways reach the central nervous system and then the efferent pathways. The nociceptors (specialized peripheral sensory neurons) start ascending pathways when detecting alarming rise of temperature, pressure and injury-related chemicals, sending alerts of potentially damaging stimuli. These stimuli are long-ranging electrical signals that are transmitted to higher brain centers, ${ }^{6,22,23}$ The nociceptors activation and their information may mediate pain sensations. $^{22,24}$ The ascending pathways activate several neural center: paleospinothalamic, archispinothalamic and neospinothalamic tracts. ${ }^{7,24}$ All these pathways have first-order neurons that are placed in back root ganglion. Each pathway originates from different areas of the spinal cord and reaches the central nervous system (CNS). ${ }^{6,25}$ The CNS is the detector and interpreter of several irritant mechanical, chemical and thermal stimuli. When intense, these stimuli elicit pain. If damaging conditions persist, pain produces hypersensitivity. ${ }^{7,26,27}$ Data on place, quality, intensity and time of pain, are processed by the sensory system while other systems cooperated to understand perceived pain. ${ }^{28,29}$ Eventually, 

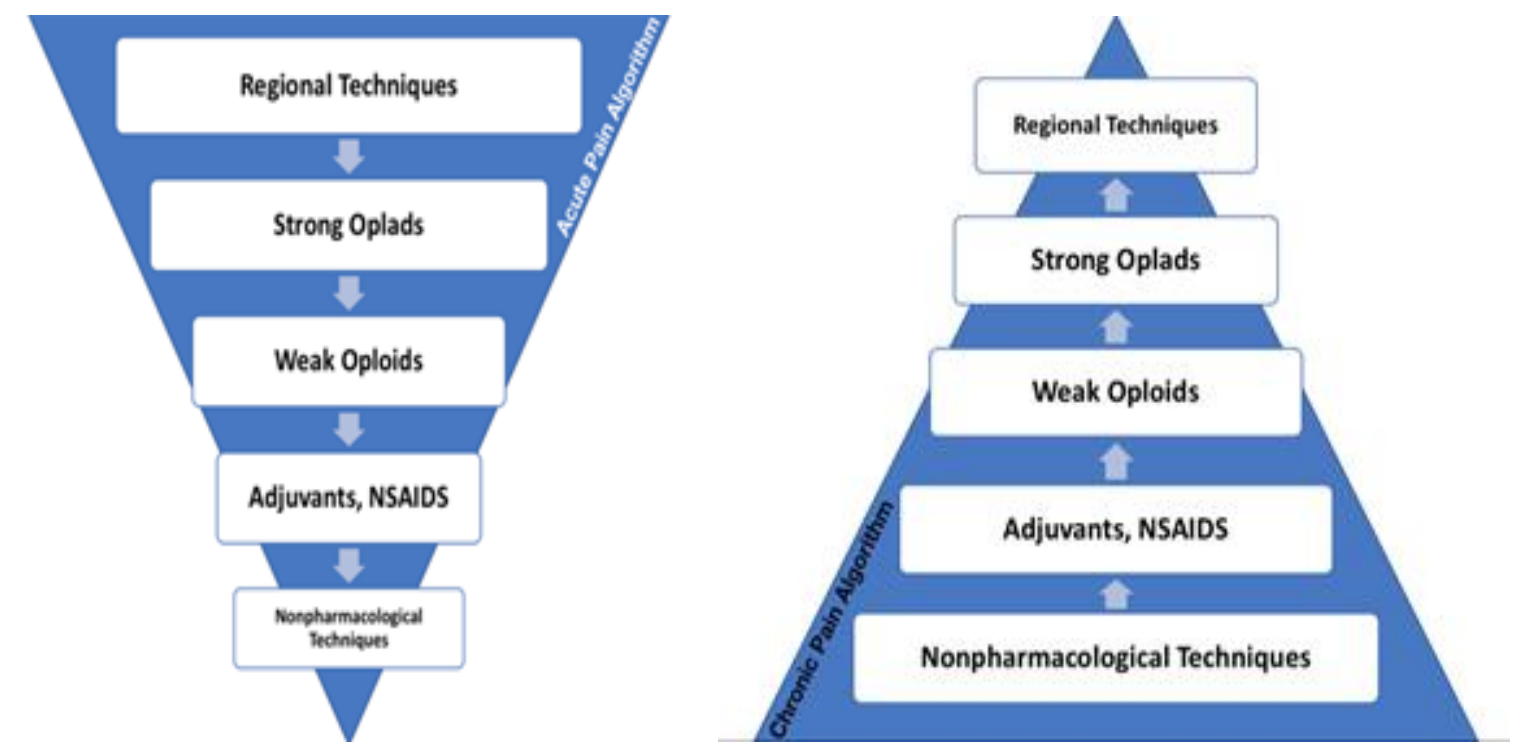

Fig 2. Management of pain: diagram of acute and chronic pain algorithm of acute pain the first treatment starts with zonal methods because of early improvement in acute pain, therapies are transferred as suitable to changing medications of PO opioid and non-pharmacological technique when severe pain is expected, nonpharmacological management can be additional at start of therapy for patient comfortably . for chorionic algorithms of pain treatment is performed with non-pharmacological method. ${ }^{3}$.

the cognitive system analyzing pain causes pain modulations. No opioid pharmacologic therapies and integrative non-pharmacologic multidisciplinary treatments of analgesia are drugs and approaches effective for both acute and chronic pain management. These drugs may enhance life quality of many patients. ${ }^{32-}$ ${ }^{34}$ Pharmacologic treatments include non opioids like NSAIDs and Adjuvants. ${ }^{35}$ Figure 1 is an overview of the factors of multidisciplinary pain administration treatment. $^{3}$

Here figure illustrates the principal treatment elements in multidisciplinary acute and chronic pain management treatment. In children's acute pain, also for pain redaction, multidisciplinary treatment efficacy is investigated with needed opioid doses decreasing to attain comfort. While In children's chronic pain, for measurement of improvements obtained through this treatment, functional improvement is a measured combination of pharmacologic therapy with zonal intervention, unification non-pharmacological method and energize service is useful to the management of pain, pain sings and life quality improvement. ${ }^{3}$

Multimodality therapy combines more than one method of treatment. ${ }^{3}$ This method that includes various medicines is optimal for the management of acute pain (Figure 2). Immediate analgesia suffices to permit the improvement from therapeutic treatments/methods with minimal side effects is the primary aim of this method. The treatment approach of multimodal painkiller targets to combine a few opioids of the nociceptive and neuropathic pain physiology while acute pain management has historically emphasized the use of opioids. Acetaminophen, Nonsteroidal antiinflammatory drugs (NSAIDs), and glucocorticoids are nociceptive painkillers. Neuropathic analgesics generally include gabapentinoids, lidocaine, ketamine, and alpha 2 agonists. Localized anesthesia and injection of regional anesthetics in a special surgical region are used regularly to allow targeted analgesia. They might assist to decrease the requirement for opioid treatments and these medications are harmless and useful analgesia and sedation. ${ }^{3,36-40}$ For acute pain management in children, presence of a psychologist or child life specialist into the therapy team reduces post-operative pain and anxiety by educating the Pediatric about therapeutic procedures, a plan of pain management, and implementing behavioral pain management interventions (e.g., distraction, play, active relaxation training) in the perioperative period. ${ }^{41,42}$ Another person who manages pediatric pain is an acupuncturist or massage therapist during therapeutic plans and operations. ${ }^{43,44}$ For acute pain in children, utilizing integrative non-pharmacological treatments within multidisciplinary analgesia methods can reduce anxiety about surgery and procedural pain, ${ }^{45-49}$ and therefore reduce pediatrics' confidence in pharmacological interventions like opioids and benzodiazepines $^{3}$

In chronic pain management, the methods of pain change from immediate analgesia to widespread pain administration co-operation and Facilitate performance 
in areas. So, for chronic pain management, the multidisciplinary method (Figure 2) is a very important standard of care in pediatric pain management. ${ }^{50,51}$ One of the most advantages of multidisciplinary chronic pain management of complex patients is applying integrative non-pharmacological therapies and pharmacological interventions simultaneous Unlike other methods using integrative non-pharmacological treatments only when all pharmaceutical medicine options have been consumed. ${ }^{3,52-60}$

Disadvantages of opioids like constipation, nausea, and vomiting has minimized their use in chronic pain management. ${ }^{13,14}$ Clinically if opioids are necessary Tramadol or Hydrocodone (weak opioids) can be prescribed in the primary treatment period however in tough pain more potent opioids should be prescribed. ${ }^{3}$ Treatment and management of pain are necessary for children to care for controlling complications attributed to uncharted pain. Pain evaluation should be periodic. Intensity, place, and source of pain must be determined .appropriate pain evaluation in children is difficult because of low verbalization and understanding of the injury. There is a beneficial evaluation method for each age group. Management of pain such as pharmacological and integrative non-pharmacological therapies has been indicated to be useful in acute and chronic pain treatment. Opioids and opioid-sparing agents as a pharmacological intervention target nociceptive and neuropathic pain physiology specific aspects. With due attention to available research, a combination of pharmacological and integrative non pharmacological treatment is indicated soon in the children's pain management. Future suggestions for pediatric pain management contains efficiency of greater trials in children all over interventions of integrative non-pharmacological pain, evaluation of the synergistic potential of combined integrative non-pharmacological therapies and more study on transferring from acute to chronic pain management.

\section{List of acronyms}

CNS. - Central nervous system

EBM- Evidence-based medicine

GIM - Global Index Medicus

IASP- International association for the Study of Pain

NSAIDs - Nonsteroidal anti-inflammatory drugs

WHO - World Health Organization

\section{Author's contributions}

All authors played a substantial role in data acquisition and analysis, and also in conception and revision of the manuscript.

\section{Acknowledgments None}

Funding No funding was received for this study.

\section{Conflict of Interest}

The authors have no conflicts to disclose.

\section{Ethical Publication Statement}

We confirm that we have read the Journal's position on issues involved in ethical publication and affirm that this report is consistent with those guidelines.

\section{Corresponding Author}

Shaqayeq Khosravi, Department of Emergency Medicine, School of Medicine, Iran University of Medical Sciences, Aliasghar children Hospital, Tehran, Iran. Phone:+98-21-22222041

Email: Khosravi.sh@iums.ac.ir

E-mail of co-author

Seyedeh Mahsa Mahmoudinezhad Dezfouli: mahmoudinejad.m@iums.ac.ir

\section{References}

1. Merskey H. Pain terms: a list with definitions and notes on usage. Recommended by the IASP Subcommittee on Taxonomy. Pain 1979;6:249-52.

2. Earp BD, Monrad JT, LaFrance M et al. Featured Article: Gender Bias in Pediatric Pain Assessment. J Pediatr Psychol 2019;44:403-14

3. Wren AA, Ross AC, D'Souza G, et al. Multidisciplinary pain management for pediatric patients with acute and chronic pain: a foundational treatment approach when prescribing opioids. Children (Basel). 2019 ;6: pii: E33.

4. Merskey H, Bogduk N. IASP Pain terminology: International Association for the Study of Pain (IASP) Taskforce on Taxonomy. 1994, Seattle, WA: IASP Press, Available at: http://www. iasppain. org/AM.

5. Laures E, LaFond C, Hanrahan K, et al. Pain assessment practices in the pediatric intensive care unit. J Pediatr Nurs 2019;48:55-62.

6. Basbaum AI, Bautista DM, Scherrer G, et al., Cellular and molecular mechanisms of pain. Cell. 2009;139:267-84.

7. Dubin AE, Patapoutian A. Nociceptors: the sensors of the pain pathway. J Clin Inves 2010;120:376072. doi: 10.1172/JCI42843.

8. Ostojic K, Paget SP, Morrow AM. Management of pain in children and adolescents with cerebral palsy: a systematic review. Developmental Medicine \& Child Neurology, 2019. 61: 315-321.

9. Epstein ME, Rodanm I, Griffenhagen G, et al. AAHA/AAFP pain management guidelines for dogs and cats. J Feline Med Surg 2015;17:251-72.

10. Monni G, Pagani G, Stagnati V, et al. How to perform transabdominal chorionic villus sampling: a practical guideline. J Matern Fetal Neonatal Med 2016;29:1499-505.

11. O'Brien T, Christrup LL, Drewes AM, et al. European Pain Federation position paper on appropriate opioid use in chronic pain management. Eur J Pain 2017;21:3-19. doi: 10.1002/ejp.970. 
12. Slater ME, De Lima J, Campbell K, et al., Opioids for the management of severe chronic nonmalignant pain in children: A retrospective 1-year practice survey in a children's hospital. Pain Med 2010;11:207-14.

13. Berde C, Nurko S. Opioid side effectsMechanism-based therapy. N Engl J Med 2008;358:2400-2.

14. Moore RA, McQuay HJ. Prevalence of opioid adverse events in chronic non-malignant pain: systematic review of randomised trials of oral opioids. Arthritis Res Therap, 2005:7;R1046.

15. Grunkemeier DM, Cassara JE, Dalton CB, et al., The narcotic bowel syndrome: clinical features, pathophysiology, and management. Clin Gastroenterol Hepatol 2007;5:1126-39.

16. Friedrichsdorf SJ. Contemporary pediatric palliative care: myths and barriers to integration into clinical care. Curr Pediatr Rev 2017;13:8-12

17. Hartman A, Rubino CM, Robinson CY. Treating pain in patients with hepatic impairment. 2019, Google Patents.

18. Boureau F, Doubrere J, LuuM. Study of verbal description in neuropathic pain. Pain 1990;42:14552.

19. Fillingim RB, Bruehl S, Dworkin RH, et al., The ACTTION-American Pain Society Pain Taxonomy (AAPT): an evidence-based and multidimensional approach to classifying chronic pain conditions. J Pain 2014;15:241-9.

20. Ibarra E, Una nueva definición de" dolor": un imperativo de nuestros días. Revista de la Sociedad Española del dolor, 2006;13:65-72.

21. Rodríguez MC, Villamor P, Castillo T. Assessment and management of pain in pediatric otolaryngology. Int $\mathrm{J}$ Pediatr Otorhinolaryngol 2016;90:138-49. doi: 10.1016/j.ijporl.2016.09.015.

22. Lauder, G. and A. Emmott, Confronting the challenges of effective pain management in children following tonsillectomy. International journal of pediatric otorhinolaryngology, 2014. 78(11): p. 1813-1827.

23. Burnstock, G., Purinergic mechanisms and pain, in Advances in Pharmacology. 2016, Elsevier. p. 91 137.

24. Roberts MH, Klatzkin RR, Mechlin B. Social support attenuates physiological stress responses and experimental pain sensitivity to cold pressor pain. Ann Behav Med 2015;49:557-69. doi: 10.1007/s12160-015-9686-3.

25. Suri M, Sharma R, Saini N. Neuro-physiological correlation between yoga, pain and endorphins. International Journal of Adapted Physical Education and Yoga 2017.

26. Becker, D.E., Nausea, vomiting, and hiccups: a review of mechanisms and treatment. Anesthesia progress 2010;57:150-7.
27. Morotti M, Vincent K, Becker CM. Mechanisms of pain in endometriosis. European Journal of Obstetrics \& Gynecology and Reproductive Biology, 2017. 209: p. 8-13.

28. Price DD. Psychological and neural mechanisms of the affective dimension of pain. Science 2000;288(5472):1769-1772.

29. McCraty R, Shaffer F. Heart rate variability: new perspectives on physiological mechanisms, assessment of self-regulatory capacity, and health risk. Global advances in health and medicine, 2015;4:46-61.

30. Buchheit T, Van de Ven T, Hsia HL, et al., Pain phenotypes and associated clinical risk factors following traumatic amputation: results from Veterans Integrated Pain Evaluation Research (VIPER). Pain Med 2016;17:149-61

31. Manworren RC, Stinson J. Pediatric pain measurement, assessment, and evaluation. Semin Pediatr Neurol 2016;23:189-200. doi: 10.1016/j. spen.2016.10.001.

32. Dowell D, Haegerich TM, Chou R. CDC guideline for prescribing opioids for chronic pain-United States, 2016. Jama, 2016;315:1624-45.

33. Nicol AL, Hurley RW, Benzon HT. Alternatives to Opioids in the Pharmacologic Management of Chronic Pain Syndromes: A Narrative Review of Randomized, Controlled, and Blinded Clinical Trials. Anesth Analg 2017;125:1682-703. doi: 10.1213/ANE.0000000000002426.

34. Gardiner P, Lestoquoy AS, Gergen-Barnett K, et al., Design of the integrative medical group visits randomized control trial for underserved patients with chronic pain and depression. Contemp Clin Trials 2017;54:25-35.

35. Tick H, Nielsen A, Pelletier KR, et al., Evidencebased nonpharmacologic strategies for comprehensive pain care: The Consortium Pain Task Force white paper. Explore (NY) 2018;14:177-211. doi: 10.1016/j.explore.2018. 02.001 .

36. Ferland CE, Vega E, Ingelmo PM. Acute pain management in children: challenges and recent improvements. Curr Opin Anaesthesiol 2018;31:327-32. doi: 10.1097/ACO.0000000000 00057 .

37. Gritsenko K, Khelemsky Y, Kaye AD, et al., Multimodal therapy in perioperative analgesia. Best Pract Res Clin Anaesthesiol 2014;28:59-79.

38. Dancel R, Liles EA, Fiore D. Acute pain management in hospitalized children. Rev Recent Clin Trials 2017;12:277-83. doi: 10.2174/ 1574887112666170816151232.

39. Friedrichsdorf SJ. Multimodal pediatric pain management (part 2). Pain Manag 2017;7:161-6. doi: 10.2217/pmt-2016-0051.

40. Dworsky ZD, Bradley JS, Brigger MT, et al. Multimodal Treatment of Rhinocerebral 
Mucormycosis in a Pediatric Patient With Relapsed Pre-B Acute Lymphoblastic Leukemia. Pediatr Infect Dis J 2018;37:5558. doi: 10.1097/INF.0000000000001839.

41. Panella JJ. Preoperative care of children: strategies from a child life perspective. AORN J 2016;104:1122. doi: 10.1016/j.aorn.2016.05.004.

42. Gordon DB, de Leon-Casasola OA, Wu CL, et al. Research gaps in practice guidelines for acute postoperative pain management in adults: findings from a review of the evidence for an American Pain Society Clinical Practice Guideline. J Pain 2016;17:158-66. doi: 10.1016/j.jpain.2015.10.023.

43. Suresh S, Wang S, Porfyris S, et al, Massage therapy in outpatient pediatric chronic pain patients: do they facilitate significant reductions in levels of distress, pain, tension, discomfort, and mood alterations? Paediatr Anaesth 2008;18:884-7. doi: 10.1111/j.1460-9592.2008.02638.x.

44. Wang SM, Escalera S, Lin EC, et al. Extra-1 acupressure for children undergoing anesthesia. Anesth Analg 2008;107:811-6. doi: 10.1213/ane. 0b013e3181804441.

45. Brewer S, Gleditsch SL, Syblik D et al., Pediatric anxiety: child life intervention in day surgery. J Pediatr Nurs 2006:21:13-22.

46. Manyande A, Cyna AM, Yip P, et al. Nonpharmacological interventions for assisting the induction of anaesthesia in children. Cochrane Database Syst Rev 2015;7:CD006447. doi: 10.1002/14651858.CD006447.pub3.

47. Singhal NR, Jones J2, Semenova J, et al., Multimodal anesthesia with the addition of methadone is superior to epidural analgesia: A retrospective comparison of intraoperative anesthetic techniques and pain management for 124 pediatric patients undergoing the Nuss procedure. $\mathbf{J}$ Pediatr Surg 2016;51:612-6. doi: 10.1016/j.jped surg.2015.10.084.

48. Monitto CL, Hsu A, Gao S, et al. Opioid prescribing for the treatment of acute pain in children on hospital discharge. Anesth Analg 2017;125:211322. doi: 10.1213/ANE.0000000000 002586.

49. Dyer SM, Harrison SL, Laver K,et al. An overview of systematic reviews of pharmacological and nonpharmacological interventions for the treatment of behavioral and psychological symptoms of dementia. Int Psychogeriatr 2018;30:295-309. doi: 10.1017/S10 41610217002344.

50. Hechler T, Martin A, Blankenburg M, et al. Specialized multimodal outpatient treatment for children with chronic pain: Treatment pathways and long-term outcome. Eur J Pain 2011;15:976-84. doi: 10.1016/j.ejpain.2011.03.001.

51. Reinecke H, Weber C, Lange K, et al. Analgesic efficacy of opioids in chronic pain: recent metaanalyses. Br J Pharmacol 2015;172:324-33. doi: 10.1111/bph.12634

52. Hechler T, Dobe M, Kosfelder J , et al., Effectiveness of a 3-week multimodal inpatient pain treatment for adolescents suffering from chronic pain: statistical and clinical significance. Clin J Pain 2009;25:156-66. doi: 10.1097/AJP. 0b013e318185c1c9.

53. Hechler T, et al., Effectiveness of a multimodal inpatient treatment for pediatric chronic pain: a comparison between children and adolescents. European Journal of Pain 2010:14 p. 97. e1-97. e9.

54. Ambrose KR, Golightly YM. Physical exercise as non-pharmacological treatment of chronic pain: why and when. Best practice \& research clinical rheumatology 2015;29:120-30.

55. Saboute M, Kashaki M, Bordbar A, et al. The Incidence of Respiratory Distress Syndrome among Preterm Infants Admitted to Neonatal Intensive Care Unit: A Retrospective Study. Open J Pediatr 2015:5;285-9

56. Kashaki, M, Mazouri A, Bordbar A, et al. Effect of Protein Supplementation on the Growth of Infants Weighing Less than 1,000 Grams Hospitalized on the Neonatal Intensive Care Unit of Akbar Abadi Hospital in Tehran, Iran (2015-2016). Iranian J Neonatol 2018;9:49-56.

57. Kashaki M, Samghabadi FM, Bordbar A.Effect of Fortification of Breast Milk in Conjugation with Protein Supplement on Neurodevelopment of Preterm Low Birth Weight Infants at 3 Years. Med Arch 2019;73:344-50.

58. Kashaki M, Bordbar A, Mazouri A, et al. Determination of the Effect of High-Dose Intralipid in Compared to Its Gradual Dose in Very Low Birth Weight Newborns: A Case-control Study. J Pharma Res Int 2019;30:1-7.

59. Moghtadaei M, Otoukesh B, Bodduhi B, et al.Evaluation of Patellar Position before and After Medial Opening Wedge High Tibial Osteotomy: Radiographic and Computed Tomography Findings. Med Arch 2016;70:293-5.

60. Yeganeh A, Otoukesh B, Kaghazian P, et al.Evaluation of the Etiologies of Implant Fracture in Patients With Fractures of the Implants of Lower Limbs' Long Bones. Med Arch 2015;69:405-8.

Submission: November, 8, 2019

Acceptance: December 15, 2019 